\title{
ANTIBIOTIC SENSITIVITY OF THE GENUS PROTEUS
}

\author{
BY \\ J. C. F. POOLE \\ From the Division of Laboratories, Radcliffe Infirmary, Oxford
}

(RECEIVED FOR PUBLICATION JANUARY 27, 1954)

The classification of the genus Proteus is still to some extent controversial, although recent investigations have clarified the position considerably. The basis of the modern work was the demonstration by Moltke (1927) that 194 Proteus strains all rapidly hydrolysed urea. For the purposes of this paper, the genus Proteus includes all motile, Gramnegative, straight rods which do not ferment lactose, do ferment glucose, and hydrolyse urea rapidly. (With a stab culture in a solid urea-containing medium a positive result is obtained in less than four hours.) On such a basis, Rustigian and Stuart (1943) proposed to include in the genus four species: $P$. vulgaris, $P$. mirabilis, $P$. morgani, ${ }^{*}$ and $P$. rettgeri, which can be readily differentiated on the basis of a few simple biochemical reactions. Cook (1948) studied the cultural characteristics of the genus more fully and showed the relative frequency of the four species.

For the purposes of routine identification it is justifiable to determine the species on the basis of three characteristics only; sucrose fermentation in 24 hours, mannitol fermentation, and indole production, as shown in Table I.

TABLE I

FERMENTATION REACTIONS AFTER 24 HOURS' INCUBATION

\begin{tabular}{|c|c|c|c|c|}
\hline & P. vulgaris & P. mirabilis & P. morgani & $P$. rettgeri \\
\hline $\begin{array}{l}\text { Sucrose } \\
\text { Mannitol } \\
\text { Indole }\end{array}$ & $\begin{array}{c}\mathbf{A G} \\
+ \\
+\end{array}$ & $\begin{array}{l}- \\
\overline{-}\end{array}$ & $\frac{-}{+}$ & $\begin{array}{l}\overline{\mathbf{A}} \\
+\end{array}$ \\
\hline
\end{tabular}

$P$. rettgeri has had a rather chequered career. It was originally described by Rettger and Harvey in 1908 as the cause of a disease in fowls, and has been known at different times as Bacillus rettgeri, Bacterium rettgeri, Eberthella rettgeri, and Shigella rettgeri. Its inclusion in the genus Proteus is based

* This organism is usually referred to as $P$. morganii in the American literature. I have followed the usual English spelling, which seems to have historical priority. mainly on its similarity to the other species in respect of urease production, but it has other features in common. On $1 \%$ agar it shows the characteristic swarming behaviour which $P$. vulgaris and $P$. mirabilis give on most solid, non-inhibitory media. $P$. rettgeri is a common and not unimportant organism. Ten per cent. of faecal Proteus strains isolated by Cook (1948) were $P$. rettgeri and an even larger proportion is found among strains from urinary infections.

\section{Material and Methods}

Forty-six Proteus strains have been tested for sensitivity to streptomycin, chloramphenicol, aureomycin, and terramycin. These comprise all strains isolated in the Oxford Public Health Laboratory and in the Bacteriology Department of the Radcliffe Infirmary, Oxford, during October and November, 1952. None have been omitted except that only one strain from each patient has been included. The majority were from hospital in-patients, but many were from faecal specimens sent in from further afield, so that these should be a reasonably representative group.

The usual tube technique has been followed in estimating sensitivity. Doubling dilutions of a solution of the antibiotic were mixed with a weak suspension of organisms from a young culture in Wright's broth and incubated overnight. All strains were tested over a range from 50 units or microgrammes per millilitre down to $1 \frac{1}{2}$ units or microgrammes per $\mathrm{ml}$. No attempt has been made to investigate the sensitivity of these organisms to higher concentrations, since sensitivity to higher concentrations is of little therapeutic value.

\section{Results}

The sensitivities of 46 Proteus strains grouped according to species are shown in Tables II, III, IV, and V. In Tables II to $\mathrm{V}$ a dash indicates resistance to 50 units or $\mu \mathrm{g}$. per $\mathrm{ml}$., and the numbers the lowest concentration to which the organ ism was sensitive.

Twenty strains of $P$. mirabilis were all reasonably sensitive to chloramphenicol. Streptomycin seems 
TABLE II

RESULTS OF SENSITIVITY TESTS ON 20 STRAINS OF PROTEUS MIRABILIS

\begin{tabular}{|c|c|c|c|}
\hline Streptomycin & Chloramphenicol & Aureomycin & Terramycin \\
\hline $\begin{array}{r}12 \\
6 \\
6 \\
12 \\
12 \\
12 \\
12 \\
12 \\
12 \\
12 \\
25 \\
25 \\
50 \\
50 \\
50 \\
50 \\
25 \\
12 \\
6\end{array}$ & $\begin{array}{c}12 \\
6 \\
12 \\
1.5 \\
6 \\
12 \\
12 \\
12 \\
6 \\
3 \\
25 \\
12 \\
25 \\
1 \cdot 5 \\
12 \\
12 \\
3 \\
3 \\
12 \\
12\end{array}$ & $\begin{array}{l}\overline{50} \\
50 \\
50 \\
= \\
= \\
= \\
= \\
= \\
= \\
= \\
= \\
=\end{array}$ & $\begin{array}{l}= \\
\bar{z} \\
= \\
\bar{z} \\
\bar{z} \\
\overline{50} \\
\overline{5} \\
\overline{50} \\
=\end{array}$ \\
\hline
\end{tabular}

TABLE III

RESULTS OF SENSITIVITY TESTS ON EIGHT STRAINS OF PROTEUS RETTGERI

\begin{tabular}{c|c|c|c}
\hline Streptomycin & Chloramphenicol & Aureomycin & Terramycin \\
\cline { 2 - 4 } 二 & Z & 3 & 25 \\
二 & Z & 3 & 1.5 \\
二 & $=$ & 12 & 6 \\
二 & $=$ & 12 & $1 \cdot 5$ \\
& $=$ & 12 & 3 \\
& & 1.5 & 25 \\
\hline
\end{tabular}

TABLE IV

RESULTS OF SENSITIVITY TESTS ON 12 STRAINS OF PROTEUS MORGANI

\begin{tabular}{c|c|c|c}
\hline Streptomycin & Chloramphenicol & Aureomycin & Terramycin \\
\cline { 1 - 3 }$-\frac{6}{1}$ & 6 & 6 & - \\
6 & $1 \cdot 5$ & 3 &.- \\
6 & 3 & 12 & $1 \cdot 5$ \\
$\frac{3}{6}$ & 12 & 25 & 3 \\
50 & 50 & 50 & -3 \\
6 & 3 & 50 & - \\
3 & 6 & 3 & $1 \cdot 5$ \\
3 & 6 & 6 & $1 \cdot 5$ \\
- & 25 & 25 & 3 \\
\hline
\end{tabular}

TABLE $V$

RESULTS OF SENSITIVITY TESTS ON SIX STRAINS OF PROTEUS VULGARIS

\begin{tabular}{c|c|c|c}
\hline Streptomycin & Chloramphenicol & Aureomycin & Terramycin \\
\cline { 2 - 3 } & 6 & 25 & 12 \\
12 & $\frac{6}{Z}$ & 25 & 12 \\
Z & 7 & 3 & 3 \\
- & 3 & - & - \\
\hline
\end{tabular}

to be slightly less effective, but the only strain resistant to 50 units per ml. was from a patient under treatment with streptomycin for pulmonary tuberculosis. On the other hand, all of these organisms were relatively resistant to aureomycin and terramycin.

The results with eight strains of $P$. rettgeri are in complete contrast. All strains were resistant to streptomycin and chloramphenicol, but all were sensitive to aureomycin and terramycin.

Twelve strains of $P$. morgani gave less consistent results, but on the whole this seems to be the most sensitive group. Most of them seem to be sensitive both to chloramphenicol and to aureomycin, unlike the mirabilis and rettgeri types.

Only six $P$. vulgaris strains are included in this series and these showed greater variation in the pattern of antibiotic sensitivity than the other species. However, it may be relevant to record the fact that these six can be divided into three groups of two strains each, giving three pairs of strains in each of which similar fermentation reactions are apparently correlated with similar antibiotic sensitivities. First, two strains which fermented sucrose, maltose, and salicin were sensitive to all four antibiotics. Secondly, two which fermented sucrose and maltose but not salicin were sensitive to aureomycin and terramycin but not to streptomycin or chloramphenicol. The third group comprises two strains which fermented sucrose but not maltose or salicin and were sensitive to chloramphenicol only. Evidently this is the most heterogeneous group both in its biochemical reactions and in its antibiotic sensitivity pattern.

\section{Discussion}

The pattern of sensitivity to antibiotics of Proteus strains seems to be correlated to some extent with their classification into four species. Two of the species show quite striking uniformity in that $P$. mirabilis was sensitive to streptomycin and chloramphenicol and $P$. rettgeri was sensitive to aureomycin and terramycin. However, it must be emphasized that this is a comparatively small series collected in one centre over a short period of time, and until a much larger number of observations have been accumulated it would be unwise to infer that the findings in this series are universally applicable.

It is suggested that the sensitivities of Proteus strains should be tested with streptomycin, chloramphenicol, aureomycin, and terramycin as, with four exceptions, the strains were sensitive to 12 units or microgrammes per $\mathrm{ml}$. or less of at least one antibiotic. 


\section{Summary}

The sensitivity of 46 Proteus strains to streptomycin, chloramphenicol, aureomycin, and terramycin has been investigated over a range of 1.5 to 50 units or microgrammes per millilitre.

Twenty strains of $P$. mirabilis were sensitive to chloramphenicol and all but one to streptomycin, but were relatively resistant to aureomycin and terramycin.

Eight strains of $P$. rettgeri were sensitive to aureomycin and to terramycin but not to streptomycin or to chloramphenicol.

Twelve strains of $P$. morgani were on the whole more sensitive than those of the other species, most of them being sensitive both to chloramphenicol and to aureomycin in contrast to $P$. mirabilis and $P$. rettgeri.

In the $P$. vulgaris group, greater variation was found.

My thanks are due to Dr. R. L. Vollum and Dr. G. T. Cook for constant advice and encouragement.

\section{REFERENCES}

Cook, G. T. (1948). J. Path. Bact., 60, 171.

Moltke, O. (1927). Contributions to the characterization and systematic classification of Bac. proteus vulgaris (Hauser). Levin and Munksgaard, Copenhagen.

Rettger, L. F., and Harvey, S. C. (1908). J. med. Res., 18, 277.

Rustigian, R., and Stuart, C. A. (1943). Proc. Soc. exp. Biol., N.Y. 53, 241. 